CONGENITAL HEART DISEASE

\title{
Cardiac troponin I release after transcatheter atrial septal defect closure depends on occluder size but not on patient's age
}

\author{
A Tárnok, J Bocsi, P Osmancik, H-J Häusler, P Schneider, I Dähnert
}

Heart 2005;91:219-222. doi: 10.1136/hrt.2003.029884

See end of article for authors' affiliations

....................

Correspondence to: Dr Attila Tárnok, Department of Paediatric Cardiology, Heart Centre, University of Leipzig, Strümpell strasse 39 04289 Leipzig, Germany; tarnok@medizin.unileipzig.de

Accepted 27 April 2004

\begin{abstract}
Objective: To examine whether transcatheter closure of secundum atrial septal defect (ASD) with the Amplatzer septal occluder leads to more myocardial injury in children than in adults.

Design: In a prospective study with children and adults cardiac troponin I (cTnl) serum concentrations were determined by immunoassay (AxSYM, Abbott Laboratories) before, during, and up to 20 months after surgical or transcatheter ASD closure.

Patients: Four groups of patients were studied: transcatheter ASD closure (group 1: 22 children, age range 3.26-14.7 years; group 2: 22 adults, 18.0-67.3 years), surgical ASD closure (group 3: 18 children, 3.12-13.5 years), and diagnostic catheterisation (group 4: 12 children, 2.68-15.0 years).

Results: cTnl concentrations were significantly increased after occluder implantation with higher serum concentrations in children than in adults (immediately after implantation: group 1, $3.2(4.4) \mu \mathrm{g} / \mathrm{l}$; group 2, 1.1 (4.2) $\mu \mathrm{g} / \mathrm{l}$; four hours after implantation: group 1, 4.8 (5.0) $\mu \mathrm{g} / \mathrm{l}$; group 2, 1.7 (2.3) $\mu \mathrm{g} / \mathrm{l}$; both $\mathrm{p}<0.01$, group $1 \vee$ group 2; one day after implantation: group 1, 3.0 (5.7) $\mu \mathrm{g} / \mathrm{l}$; group 2, 2.2 (5.2) $\mu \mathrm{g} / \mathrm{l})$ but were less than $20 \%$ of those after surgical ASD closure (group 3; $p<0.001$ ) where the highest cTnl concentration was found (37.1 (26.3) $\mu \mathrm{g} / \mathrm{l})$. Diagnostic catheterisation (group 4) was not associated with detectable cTnl increase. From the cTnl concentrations the total amount of cTnl released after ASD closure was estimated for each patient. This was dependent on the size of the occluder $(p<0.05)$ but not on the patient's age or procedural duration.

Conclusion: In regard to interventional ASD closure our data do not provide evidence that the child's myocardium is more vulnerable. Transcatheter ASD closure induces minor myocardial lesion, the extent of which depends on the size of the Amplatzer septal occluder but is irrespective of the patient's age.
\end{abstract}

$\mathrm{T}$ he Amplatzer septal occluder has proved to be a versatile and safe system for the occlusion of secundum atrial septal defect (ASD) and its high success rate has led to its widespread use. ${ }^{1-4}$ Interventional ASD occlusion produces much lower myocardial damage ${ }^{5}$ than does surgical ASD closure. ${ }^{6}$ However, little is known about myocardial lesions after occluder implantation in children. There are indications that the sensitivity of the myocardium to surgical trauma is inversely related to the patient's age, with higher vulnerability among children.

Cardiac troponin I (cTnI) is a sensitive and specific marker for myocardial damage. It is detectable only in traces in the peripheral blood of healthy people. ${ }^{78} \mathrm{CTnI}$ increase is widely used for the diagnosis of myocardial infarction ${ }^{8}$ and its concentration is increased after cardiac surgery ${ }^{70} 11$ with maximum values $6-10$ hours after surgery. ${ }^{71}$ The duration of ischaemic time correlates most strongly with the release of cTnI. ${ }^{7}$ Catheter intervention and radiofrequency ablation also lead to myocardial injury with increased cTnI. ${ }^{12}{ }^{13}$ The specific mechanism of myocardial injury in interventional ASD closure in not yet fully understood. The influence of the size of the defect and of the closure device has not been studied. It is not clear whether the size of the septal defect also contributes to myocardial damage.

To investigate the effect of age on myocardial damage related to occluder implantation we measured the serum concentrations of cTnI before and after catheter intervention in children and adults and compared the data with surgical ASD closure and diagnostic cardiac catheterisation.

\section{METHODS}

\section{Patients and study design}

Four groups of patients were studied prospectively (table 1): children (group $\mathrm{l}, \mathrm{n}=22$ ) and adults (group 2, $\mathrm{n}=22$ ) who underwent Amplatzer occlusion of ASD (occluder diameter $12-34 \mathrm{~mm}$, implantation with transoesophageal echocardiography and fluoroscopy guidance, exclusion criterion diagnostic endomyocardial biopsy), children (group 3, $\mathrm{n}=18$ ) with surgical ASD closure (ASD closure by a homologous pericardial patch with median sternotomy, extracorporeal circulation, bypass time 27-58 minutes with aortic cross clamping $12-35$ minutes, hypothermia $28-35^{\circ} \mathrm{C}$, hypothermia time 20-60 minutes, postoperative mechanical ventilation 4-6 hours), and children (group 4, n = 12) with diagnostic cardiac catheterisation without intervention (ventricular septal defect $(\mathrm{n}=5)$, coarctation of the aorta $(\mathrm{n}=5)$, other diagnosis $(\mathrm{n}=2))$. The study was reviewed by the ethical committee of the University of Leipzig and informed consent was obtained from patients or their parents before the individual procedure. Pulmonary to systemic flow ratios in groups 1, 2, and 3 ranged from 1.5:1 to 3:1. Amplatzer septal occluders were implanted under intubation with propofol, alfentanil, and cisatracurium in 12 children (group 1) and 16 adults (group 2). All other patients of group 1 and 2 received midazolam and propofol alone; the complete procedure was performed while spontaneous breathing

Abbreviations: ASD, atrial septal defect; AUC, area under the curve; cTnl, cardiac troponin I 
Table 1 Characteristics of the patient groups

\begin{tabular}{|c|c|c|c|c|}
\hline & $\begin{array}{l}\text { Group 1: children } \\
\text { with Amplatzer } \\
\text { ( } n=22 \text { ) }\end{array}$ & $\begin{array}{l}\text { Group 2: adults } \\
\text { with Amplatzer } \\
(\mathrm{n}=22)\end{array}$ & $\begin{array}{l}\text { Group 3: children } \\
\text { with surgery } \\
(n=18)\end{array}$ & $\begin{array}{l}\text { Group 4: children } \\
\text { with catheterisation } \\
\text { ( } n=12 \text { ) }\end{array}$ \\
\hline Age (years) & $8.3(3.6)^{*}$ & $44.4(17.4)^{\star *}$ & $7.0(2.4)$ & $9.2(3.9)$ \\
\hline Range & $3.26-14.7$ & $18.0-67.3$ & $3.12-13.5$ & $2.68-15.0$ \\
\hline Weight (kg) & $29.8(15.1)$ & $73.4(17.4)^{\star *}$ & $20.7(7.0)$ & $35.4(18.2)$ \\
\hline Sex (female/male) & $14 / 8$ & $12 / 10$ & $11 / 7$ & $5 / 7$ \\
\hline Duration of procedure (min) & $42.2(13.1)$ & $38.8(12.3)$ & $39.3(9.8) \dagger$ & $46.6(15.7)$ \\
\hline
\end{tabular}

without intubation was maintained. In group 3 general anaesthesia and myoplegia were performed with midazolam, fentanyl, and pancuronium.

\section{Sampling and assays}

In groups $1-3$ blood samples $(0.5 \mathrm{ml})$ were taken one day before intervention or surgery $(-1$ day); immediately after anaesthesia onset before surgery or at the beginning of the catheterisation immediately after insertion of the sheaths, immediately after intervention with removal of the sheaths, or at the end of surgery during rewarming (+l hour); and four hours $(+4$ hours), one day $(+1$ day, at a mean $(S D)$ of 24.1 (3.0) hours), one to six weeks ( +1 week), and two to 20 months (+2 months) after intervention or surgery. In group 4 no blood was collected at +4 hours and at +2 months. cTnI was measured by AxSYM ${ }^{14}$ microparticle enzyme immunoassay (Abbott Laboratories; cut off value $0.1 \mu \mathrm{g} / \mathrm{l}$ ). The area under the curve (AUC), representative of the total release of cTnI in $1 \mathrm{ml}$ (cTnI-AUC) was calculated. ${ }^{7}$ To take into

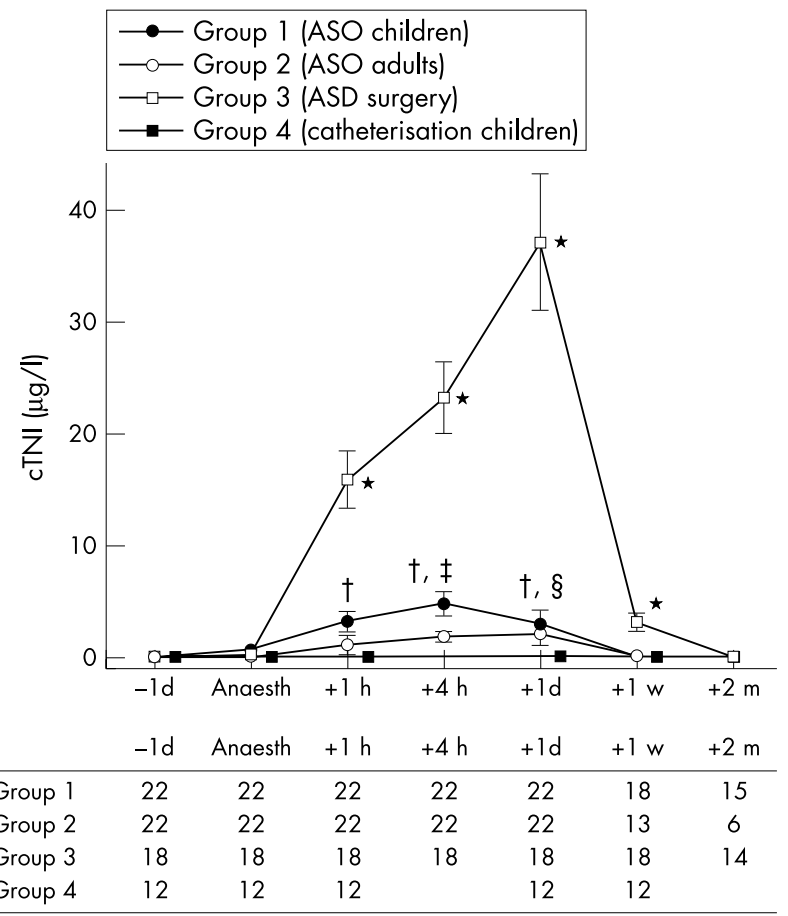

Figure 1 Time course of cardiac troponin I (cTnl) serum concentrations before, during, and after interventional (groups 1 and 2), surgical atrial septal defect (ASD) closure (group 3), or diagnostic cardiac catheterisation (group 4). Data are mean (SD). ASO, Amplatzer septal occluder. ${ }^{*} p<0.005$, group $3 \vee 1,2$, and $4 ;+p<0.040$, group $1 \vee 4$; $\neq p<0.010$, group $1 \vee 2 ; \S p<0.005$, group $2 \vee 4$. account the differences in the total blood volume between children and adults cTnI-AUCs were weighted with the patients estimated blood volume (bodyweight $\times 80 \mathrm{ml}$ ) as a measure of the overall cTnI release for each patient.

\section{Statistical analysis}

Data were tested for normal distribution by the KolmogorovSmirnov test. Changes with time within a group were tested by the non-parametric Friedman test; time courses were compared between groups with analysis of variance for repeated measures. Statistical differences between groups were tested by Student's $t$ test, Mann-Whitney $U$ test, or Wilcoxon test, as appropriate. Bivariate cross correlation was determined according to Pearson. Differences were regarded as significant if $\mathrm{p}<0.05$ (all statistical calculations done with SPSS version 8.0, Knowledge Dynamics, Canyon Lake, Texas, USA).

\section{RESULTS}

Among all patients of groups 1, 2, and 3 the entire procedure and course were uneventful and the ASD was closed successfully with no detectable residual shunt on colour Doppler at +1 day (groups 1 and 2) or at discharge (group 3). Diagnostic cardiac catheterisation was uneventful in all patients.

\section{cTnl serum concentrations}

cTnI concentrations were increased immediately after ASD closure until +1 day in groups 1 and 2 and until +1 week in group 3 (all p $=0.0005$, Friedman; $p=0.005$, analysis of variance groups 1, 2, and 3 versus group 4) (fig 1). The highest concentrations were reached as early as at +4 hours (group 1) or at +1 day (groups 2 and 3). The increase was more than five times higher after surgery than after Amplatzer occlusion ( $p=0.0005$, analysis of variance group 3 versus group 1 or 2 ). At +1 week cTnI concentrations were below the cut off value in all except one patient with an Amplatzer occluder. At this time cTnI concentrations were still measurable in group 3. In group $4 \mathrm{cTnI}$ concentrations remained below the cut off at all times.

\section{Total amount of released cTnl}

cTnI concentration in groups 1 and 2 did not correlate with the duration of the intervention or the size of the implant device and did not differ between patients with and patients without intubation. The mean concentration of cTnI-AUC was more than four times higher in group 3 than in groups 1 and 2 (both $\mathrm{p}=0.0001$; mean cTnI-AUC: group 1, 50.7 (55.2) $\mathrm{ng} \cdot \mathrm{h} / \mathrm{ml}$, group 2, $25.3(24.0) \mathrm{ng} \cdot \mathrm{h} / \mathrm{ml}$, group 3, $223.4(193.2) \mathrm{ng} \cdot \mathrm{h} / \mathrm{ml}$ ). In addition, the mean overall cTnI release was more than two times higher in group 3 (343 $(269) \mu \mathrm{g} \cdot \mathrm{h}$ ) than in groups $\mathrm{l}$ and 2 (group 1,103 (93) $\mu \mathrm{g} \cdot \mathrm{h}$; group $2,136(114) \mu \mathrm{g} \cdot \mathrm{h}$, group 3 versus group 1 or $2, p=0.003)$. However, cTnI at +1 hour, +4 hours, and +1 day (not shown), as well as the cTnI-AUCs after occluder 

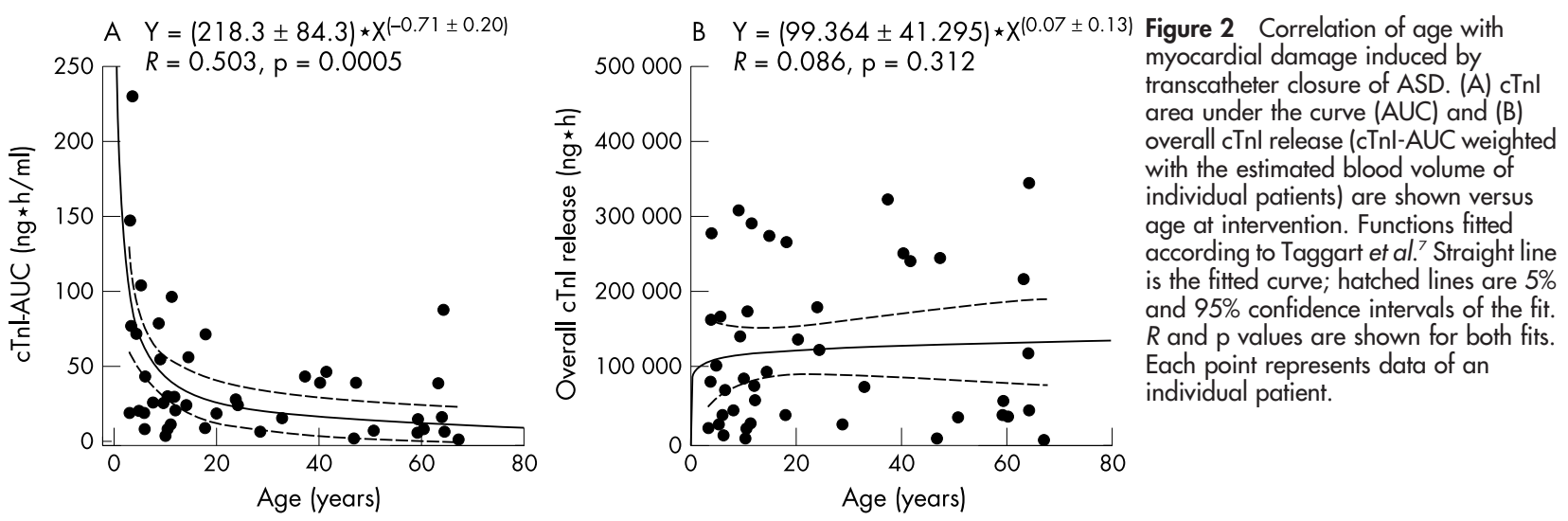

implantation, correlated negatively with the patient's age (fig 2A). In contrast, overall cTnI release (representative of the total amount of released cTnI) was not age related in groups 1, 2, and 3 (fig 2B).

In groups 1 and 2 we correlated the overall cTnI release with the patient's age, body weight, body surface area, dimensions of the device, ratio of device diameter to body surface area, and duration of the procedure. Overall cTnI release was found to correlate only with the size of the occluder in the following descending order: left atrial disc $(p=0.0002, R=0.54)$ (fig 3$)$, right atrial disc $(\mathrm{p}=0.0059, R=0.41)$, and central portion $(\mathrm{p}=0.0189$, $R=0.35)$.

\section{DISCUSSION}

It is well known that cardiac surgery leads to a transient increase in cTnI serum concentration. ${ }^{10}{ }^{11}$ Consistent with this, the highest cTnI concentrations in the present study were observed after surgical ASD closure. However, a mild and temporary rise of the cTnI concentration was also observed after occluder implantation, and this increase was more pronounced in children than in adults. cTnI concentrations after intervention show that this procedure leads to

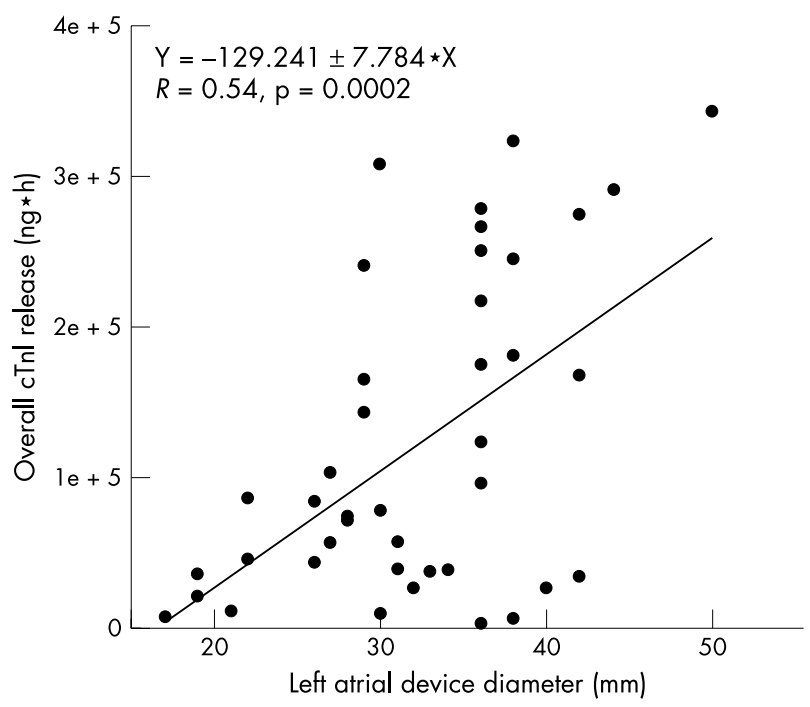

Figure 3 Correlation of myocardial damage with left atrial disc size. Overall cTnl release after myocardial damage by interventional ASD closure is shown versus size of the left atrial disc of the ASO. Linear regression: $R=0.54, \mathrm{p}=0.0002$. Each point represents data of an individual patient. transient, clinically silent myocardial damage. In our opinion this is not caused by the catheterisation because, in contrast to others, ${ }^{13}$ we found that cardiac catheterisation alone did not lead to a measurable cTnI increase. Pees and colleagues ${ }^{5}$ previously reported increased cTnI concentrations over several hours after interventional closure of interatrial communication with an Amplatzer occluder. They regarded this as a result of transient, reversible myocardial membrane instability caused by the device. ${ }^{5}$ Their study focused on older patients (mean age 43.5 years) and did not examine correlations with age or device size.

Some reports suggest that the child's myocardium is more susceptible to trauma than that of adults based on higher cTnI-AUCs after surgery at a lower age. ${ }^{7}$ However, these studies did not consider that the same amount of myocardial damage may produce a much higher $\mathrm{cTnI}$ concentration and cTnI-AUC in a smaller patient because of the lower blood volume. When the reduced blood volume of children is taken into account our data indicate that the overall cTnI release after occluder implantation shows similar myocardial damage irrespective of the patient's age. Our data do not challenge the hypothesis ${ }^{7}$ that the cardiomyocytes of children are more sensitive to mechanical trauma than are those of adults, but this seems not to be relevant to interventional ASD closure.

Our results show a significant increase in myocardial injury with the size of the Amplatzer device. Its size in turn is defined by the size of the ASD but not by the size of the heart. Because the left atrial disc is the largest part of the Amplatzer device, it has the highest correlation with overall cTnI release and has the largest contact surface with the myocardium.

Coronary interventions and radiofrequency ablation in adults cause myocardial lesion associated with a rise of cTnI concentrations. ${ }^{12}{ }^{13}$ Kannankeril and colleagues ${ }^{13}$ reported cTnI increase after catheter interventions such as balloon dilatation or stent implantation in the pulmonary artery. Endomyocardial biopsy and radiofrequency ablation produce myocardial lesions and, as expected, an increase in cTnI concentration. Ventricular strain and myocardial injury ${ }^{13}$ are assumed to be caused by balloon dilatation or positioning of stents into the pulmonary artery and may explain the cTnI increase. Implantation of an Amplatzer septal occluder may similarly lead to a mild myocardial lesion due to repeated balloon sizing and thus stretching of the interatrial septum. Furthermore, stenting of the defect may lead to some compression of the myocardial rim. The left and right atrial discs may produce pressure on the myocardium of the interatrial septum, contributing to a transient cTnI rise. Irritation or friction, however, does not seem to be continuous because two months after implantation no cTnI was detectable in the serum. Therefore, subsequent 
diagnostic troponin I measurement in suspected myocardial infarction would not be affected.

Theoretically, coronary air embolism with a somewhat more extended myocardial lesion might have been a reason for the clearly increased cTnI concentrations in two patients of the Amplatzer septal occluder group, although gross air embolism (as has been described in the literature) was not observed..$^{15}$ Despite careful and apparently complete removal of air from the sheath, air bubbles can occasionally be released when the occluder is pushed forwards through the sheath that enters the left atrium and can potentially reach the coronaries.

We conclude that implantation of the Amplatzer septal occluder in ASD induces minor and transient myocardial damage, which is substantially lower than in conventional surgical closure, is age independent, and increases with the size of the occluder.

\section{ACKNOWLEDGEMENTS}

The authors thank the Saxonian States, Ministry for Science and Arts (Sächsisches Staatsministerium für Wissenschaft und Kunst, SMWK, Dresden, Germany) for their support (research grants to JB and PO) and the German Foundation for Heart Research (Deutsche Stiftung für Herzforschung, Frankfurt, Germany) for partially funding the study. The authors also thank Mrs J Richter for technical help.

\author{
Authors' affiliations \\ A Tárnok, J Bocsi, Research Laboratory, Department of Paediatric \\ Cardiology, Heart Centre, University Hospital, Leipzig, Germany \\ P Osmancik, Cardiac Centre, Department of Paediatric Cardiology, \\ University Hospital Kralovske Vinogrady, Prague, Czech Republic \\ H-J Häusler, P Schneider, I Dähnert, Department of Paediatric \\ Cardiology, Heart Centre, University Hospital, Leipzig, Germany
}

\section{REFERENCES}

1 Dhillon R, Thanopoulos B, Tsaousis $G$, et al. Transcatheter closure of atrial septal defects in adults with the Amplatzer septal occluder. Heart 1999:82:559-62.

2 Masura J, Cavora P, Formanek A, et al. Transcatheter closure of secundum atrial septal defects using the new self-centering Amplatzer septal occluder: initial human experience. Cathet Cardiovasc Diagn 1997:42:388-93.

3 Thanopoulos B, Laskari C, Tsaousis GS, et al. Closure of atrial septal defects with Amplatzer occlusion device: preliminary results. J Am Coll Cardiol 1998;31:1110-6.

4 Vogel M, Berger F, Dähnert I, et al. Treatment of atrial septal defects in symptomatic children aged less than 2 years of age using the Amplatzer septal occluder. Cardiol Young 2000;10:534-7.

5 Pees C, Haas NA, von der Beek J, et al. Cardiac troponin I is increased after interventional closure of atrial septal defects. Catheter Cardiovasc Interv 2003:58:124-9.

6 Hirsch R, Dent CL, Wood MK, et al. Patterns and potential value of cardiac troponin I elevations after pediatric cardiac operations. Ann Thorac Surg 1998;65:1394-9.

7 Taggart DP, Hadjinikolas L, Hooper J, et al. Effects of age and ischemic times on biochemical evidence of myocardial injury after pediatric cardiac operations. J Thorac Cardiovasc Surg 1997; 1 13:728-35.

8 Bodor GS, Porter S, Landt Y, et al. Development of monoclonal antibodies for an assay of cardiac troponin-I and preliminary results in suspected cases of myocardial infarction. Clin Chem 1992;11:2203-14.

9 Adams JE, Sicard GA, Allen BT, et al. Diagnosis of perioperative myocardial infarction with measurement of cardiac troponin I. N Engl J Med 1994;330:670-744

10 Immer FF, Stocker FP, Seiler AM, et al. Troponin-l for prediction of early postoperative course after pediatric cardiac surgery. J Am Coll Cardiol 1999:33:1719-23.

11 Joost CJM, Swaanenburg JC, Loef BG, et al. Creatine kinase MB, troponin I, and troponin T release patterns after coronary artery bypass grafting with or without cardiopulmonary bypass and after aortic and mitral valve surgery. Clin Chem 2001:47:584-7.

12 Manolis AS, Vassilikos V, Maounis T, et al. Detection of myocardial injury during radiofrequency ablation by measuring serum cardiac troponin I levels: procedural correlates. J Am Coll Cardiol 1999;34:1099-105.

13 Kannankeril PJ, Wax DF, Pahl E. Elevations of troponin I after interventional cardiac catheterization. Cardiol Young 2001;11:375-8.

14 Ver Elst KM, Chapelle JP, Boland P, et al. Analytic and clinical evaluation of the Abbott AxSYM cardiac troponin I assay. Am J Clin Pathol 1999;112:739-41.

15 Hung MJ, Kuo LT, Wang CH, et al. Irreversible myocardial damage after coronary air embolism: a case report. Angiology 2002;53:213-6.

\section{IMAGES IN CARDIOLOGY}

\section{Coronary ulcer}

A

76 year old hypertensive male smoker with a family history of coronary artery disease was referred to the cardiac catheterisation unit after a prolonged episode of chest discomfort. Clinical examination, ECG, and laboratory tests were unremarkable, however, when performed after symptoms faded away.

A coronary angiogram in the right anterior oblique caudal projection (right panels: CX, circumflex artery; LAD, left anterior descending artery) revealed an ulcer with overhanging margins (arrowhead) in the proximal left anterior descending artery, most likely resulting from rupture of an atherosclerotic plaque.

Atherosclerotic lesions in native coronary arteries are contained by a fibrotic cap. Spontaneous plaque rupture occurs when this fibrous cap breaks, exposing thrombogenic lesion contents to the bloodstream. Plaque rupture is commonly associated with acute myocardial infarction or unstable angina.

Since the patient was asymptomatic at the time of coronary angiography and only a moderately stenotic lesion was found, no percutaneous coronary intervention was planned.

Dobutamine stress echocardiography was performed to discard any inducible ischaemia and the patient was discharged on

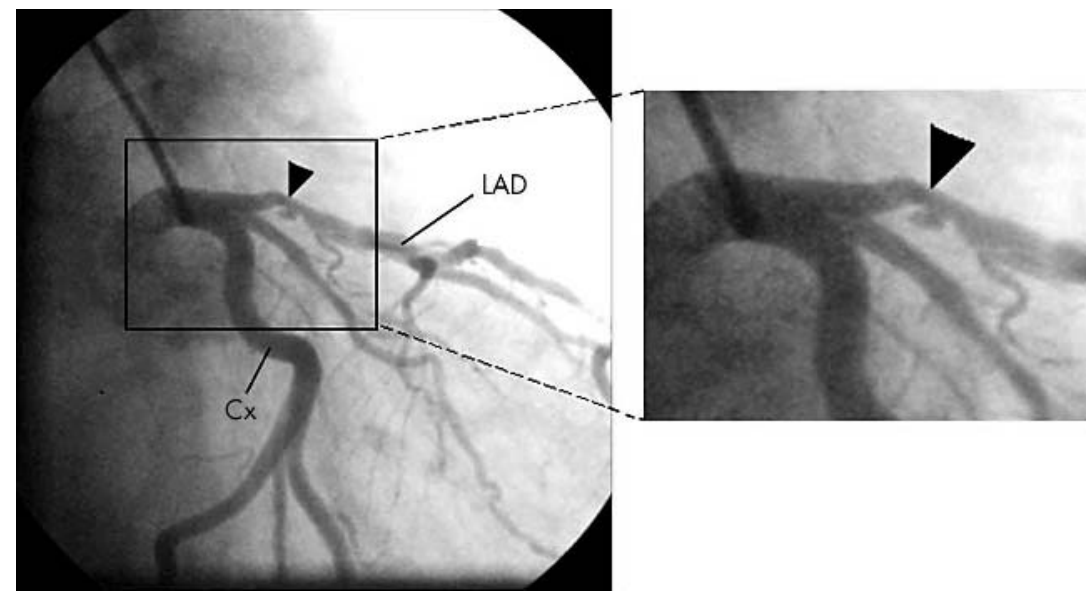

aspirin, statins, and angiotensin converting enzyme inhibitors in an attempt to pursue plaque stabilisation and improve endothelial function.

Although the patient was symptom-free, coronary angiography was performed at six months, showing no changes in the aspect of the ulcer. 